\title{
Expression of cytosolic and thiolated proteome of Musca domestica larvae under oxidative challenge
}

\author{
Tan, Y.H. and Alias, Z.* \\ Toxicology and Protein Analysis Laboratory, Institute of Biological Sciences, Faculty of Science, \\ University of Malaya, 50603 Kuala Lumpur, Malaysia \\ *Corresponding author e-mail: alias@um.edu.my \\ Received 19 July 2016; received in revised form 8 July 2017; accepted 11 July 2017
}

\begin{abstract}
The study was aimed to investigate the expression of cytosolic and thiolated proteins of Musca domestica larvae under oxidative stress. Proteins from acute treatment of hydrogen peroxide $\left(\mathrm{LC}_{50}=21.52 \%(\mathrm{v} / \mathrm{v})\right)$ on 3rd stage larvae of housefly were extracted and purified using an activated Thiol Sepharose ${ }^{\circledR}$ for thiolated protein purification. Two dimensional gel electrophoresis was used for visualizing and analyzing expression of cytosolic and thiolated proteins. Protein spots with more than 5 fold of expression change were identified using liquid chromatography- tandem mass spectrometry (LC-MS/MS). The cytosolic proteins were actin, tropomyosin, ubiquitin, arginine kinase, pheromone binding protein/general odorant binding protein, and ATP: guanidino phosphotransferase. The thiolated proteins with more than 5 fold change in expression as an effect to the acute treatment were fructose bisphosphate aldolase, short chain dehydrogenase and lactate/malate dehydrogenase. The proteins identified in the study should provide vital information for future reference in oxidative stress defence and response occurring in houseflies.
\end{abstract}

\section{INTRODUCTION}

Musca domestica (1758, Linnaeus) (Diptera: Muscidae), commonly known as housefly, is a synanthropic insect that lives in the urban areas where there are high densities of human waste as their food source (Dahlem, 2003). An adult housefly completes its metamorphosis from egg to adult stage. Housefly breeds extremely fast when compared to other species of flies. Female houseflies lay 500 eggs, in 5 to 6 batches in her lifespan, with 75 - 100 eggs deposited each batch in the span of just 3 to 4 days.

Houseflies are known to be vectors of various diseases of over 30 bacteria including Heliobacter pylori, Escherichia coli, and even methicilin resistant Staphylococcus and tiarcilin resistant Pseudomonas (Boulesteix et al., 2005; Grubel et al., 1997; Szalanski et al., 2004). Houseflies carry viruses such as Newcastle disease virus (Barin et al., 2010). Resistance of houseflies to insecticides happen across the globe (Marçon et al., 2003; Scott et al., 2000). For housefly larvae, Kristensen \& Jespersen (2003) found resistance strains against insect growth regulators. Molecular biologists are highly interested on houseflies due to their growing resistance to insecticides. Scott et al. (2009) suggested Musca domestica as a model organism for resistance studies and development of new insecticides. Insecticides including pyrethroids (Kale et al., 1999), organophosphates (Lukaszewicz-Hussain, 2010), and organochlorines (Koner et al., 1998) have known to be inducing oxidative stress.

Hydrogen peroxide are one of the nonradical reactive oxygen species. Despite its oxidizing capacities, hydrogen peroxide is constantly produced in cellular functions. In Musca domestica, GST gene family (Yin et al., 2000), SOD gene (Dabas et al., 2012) and glutathione peroxidase (Simmons et al., 1987) involve in housefly defence against 
hydrogen peroxide. Cysteine residues, the only sulfhydryl/thiol (SH) - bearing amino acid, have high reactivity and unique redox properties, forming key catalytic components of enzyme on the active site (Barford, 2004). Oxidative thiol modification by hydrogen peroxide are found to occur in enzymes and proteins such as glyceraldehyde-3phosphate dehydrogenase (GapDH) (Brandes et al., 2007), PTP-1B (protein tyrosine phosphatases-1B) (van Montfort et al., 2003) and p53 tumor suppressing factor (Velu et al., 2007).

Despite the immunity and insecticide tolerance of Musca domestica, which are vital as a model for insect biochemistry and physiology, the genome project for housefly were only initiated at 2009 (Scott et al., 2009). More importantly, to the best of our knowledge, only a handful of Musca domestica related proteomics research are available. However, during the past 5 years there is an increasing interest to understand the inner molecular workings of this insect, notably the completion of sequencing of the full genome of Musca domestica by Scott et al. (2014). Combining thiol protein trapping techniques (Hu et al., 2010), 2D-gel electrophoresis (Klose, 1975; O'Farrell, 1975) and the LC-MS/MS identification, we investigated the cytosolic proteins and thiolated proteins alike. The aim of this study was to evaluate and identify the possible responsive proteins when larvae are under oxidative stress.

\section{MATERIALS AND METHODS}

\section{Chemicals}

Unless otherwise stipulated, highest grade of chemicals was used in this research. Chemicals related with 2D gel electrophoresis were of analytical grade purchased from BioRad Laboratories, (Hercules, CA, USA) and GE Healthcare (Little Chalfont, United Kingdom). Activated Thiol-Sepharose $\mathrm{R} 4 \mathrm{~B}$ was purchased from Sigma-Aldrich (St. Louis, Missouri, USA).

\section{Musca domestica adult and larvae cultivation}

Adult Musca domestica samples were obtained from Vector Control Research Unit, World Health Organization, University of Science Malaysia, Penang, Malaysia. The flies were reared in modified plastic cages at room temperature. The adults fed on sugar and milk powder mixed on 1:1 ratio. Housefly larval was laid on surface made of Ramy Feeds hamster pellet (Bengy) soaked with distilled water in a 1:1.5 ratio. For the experiments, $3^{\text {rd }}$ stage larvae were tested.

\section{Oxidative challenge of 3rd stage larvae and determination of toxicity parameters}

$6 \mathrm{~g}$ of mouse pellet was mixed with $10 \mathrm{ml}$ of solution of different concentrations of $\mathrm{H}_{2} \mathrm{O}_{2}$ solution (concentration ranging from $15 \%, 17.5 \%, 20 \%, 22.5 \%$ and $25 \%(\mathrm{v} / \mathrm{v}) .300$ individuals of 3 day-old larvae ( $3^{\text {rd }}$ stage) (Kočišová et al., 2004) were collected, and placed to each medium of different $\mathrm{H}_{2} \mathrm{O}_{2}$ concentrations and left to feed for 24 hours. Larvae which were observed not moving were considered dead by the acute treatment. The number mortalities of the larvae were counted and subjected to PROBIT analysis (Finney, 1947). The concentration of the hydrogen peroxide which caused 50\% mortalities $\left(\mathrm{LC}_{50}\right)$ of larvae population was determined and used for proteomic investigation.

\section{Determination of lipid peroxidation}

The larvae were homogenized in homogenizing buffer $\left(0.1 \mathrm{M} \mathrm{NaH}_{2} \mathrm{PO}_{4}\right.$ buffer, $\mathrm{pH} 7.5$, $1.3 \mathrm{mM}$ EDTA, $0.1 \mathrm{mM}$ EDTA, 1\% protease inhibitor, and traces of phenylthiourea) using HG-15D homgenizer (WiseTis R) (Tedesco et al., 2010). Samples were centrifuged at $3000 \times \mathrm{g}$ for 20 minutes and then derivatized in $1 \mathrm{ml}$ of reaction mixture containing 10.3 mM 1- methyl-2-phenylindole which was dissolved in acetonitrile: methanol $(3: 1 \mathrm{v} / \mathrm{v})$ with $32 \%(\mathrm{v} / \mathrm{v}) \mathrm{HCl}$. The malondialdehyde (MDA) standard curve was produced to determine the internal concentration of MDA 
in nmol/g (wet weight). The absorbance of unknowns and standard curve were read at $586 \mathrm{~nm}$.

\section{Preparation of protein lysate and thiol protein purification}

ReadyPrep $^{\mathrm{TM}}$ Protein Extraction Kit (Cytoplasmic/Nuclear) (Bio-Rad) was used to extract cytosolic proteins from the homogenate, according to the manufacturer's protocol. $50 \mu \mathrm{l}$ of protein lysate were aliquoted and kept at $-80^{\circ} \mathrm{C}$ until further analysis.

Purification of thiols protein was performed as described by $\mathrm{Hu}$ et al. (2010). Protein lysate (with suitable protein content) was incubated with $5 \mathrm{M}$ urea for 10 minutes at room temperature. $20 \mathrm{mg}$ of activated Thiol-Sepharose ${ }^{\circledR}$ 4B (Sigma-Aldrich) and $200 \mu \mathrm{l}$ binding buffer solution ( $0.1 \mathrm{M}$ Tris-HCl pH 7.5, 0.5 M NaCl, 1 mM EDTA) were added. The samples were incubated on ice for 1.5 hours and shaken for every 15 minutes to ensure maximum binding. The gel matrix containing bound proteins were washed 8 times with $500 \mu \mathrm{l}$ of binding buffer and the unbound proteins were discarded. Finally, $200 \mu \mathrm{l}$ of binding buffer containing $25 \mathrm{mM}$ DTT was added and the matrix was incubated on ice for 1 hour with frequent gentle shaking to release all bound thiol-containing proteins. The mixture was centrifuged at $11000 \mathrm{x} g$ for 3 minutes and the protein thiol-containing proteins were collected and kept at $-80^{\circ} \mathrm{C}$ for further analysis.

\section{Protein quantitation}

Protein quantitation of the sample lysate for both total proteome and thiol protein purified samples was done by using 2-D Quant Kit (GE Healthcare) accordingly to the manufacturer's protocol. A bovine serum albumin solution of $2 \mathrm{mg} / \mathrm{ml}$ was diluted into protein content ranging from $0 \mu \mathrm{g}$ to $50 \mu \mathrm{g}$. $500 \mathrm{\mu l}$ of precipitant was added to each tube, vortexed and incubated for 2-3 minutes at room temperature. $500 \mu \mathrm{l}$ of co-precipitant was later added and vortexed. The tubes were centrifuged for $10,000 \times g$ for 5 minutes to sediment the protein. The precipitant and co-precipitant were decanted and removed. $100 \mu \mathrm{l}$ of copper solution and $400 \mu \mathrm{l}$ of deionized water were added and vortexed to dissolve the protein precipitate. $1 \mathrm{ml}$ of the working colour reagent, prepared by mixing 100 parts of colour reagent $A$ and 1 part of colour reagent $B$ of the kit was added into each tube, inverted and incubated in room temperature for 15-20 minutes. Absorbance of $480 \mathrm{~nm}$ was read for each tube with water as reference.

\section{Two dimensional gel electrophoresis}

$40 \mathrm{\mu l}$ of protein samples (protein lysate for cytosolic or the prepared thiol-containing proteins) were dissolved in $45 \mu \mathrm{l}$ of solubilizing buffer (8M urea, 4\% CHAPS, 65mM DTT, 3M thiourea, trace bromophenol blue) and $40 \mu \mathrm{l}$ of rehydration solution (8M urea, 2\% CHAPS, $0.2 \%$ (w/v) DTT, $2 \%$ carrier ampholytes (pH 3-10), traces of bromophenol blue). The mixtures were applied onto $7 \mathrm{~cm}$ Immobiline ${ }^{\mathrm{TM}}$ Drystrips, pH 3-10 NL IPG strip (GE Healthcare). The strips were rehydrated overnight for 18 hours. Isoelectric focusing were done in Multiphor III (GE Healthcare) under the voltage setup: Step 1 (Gradient): Voltage: 200V; Time: 1 minute; Current: 5mA; Power: 2W. Step 2 (Gradient): Voltage: 3500V; Time: 1.5 hours; Current: $5 \mathrm{~mA}$; Power: $2 \mathrm{~W}$. Step 3 (Gradient): Voltage: 3500V; Time: 1.5 hours; Current: 5mA; Power: 2W.

The temperature of the focusing was controlled by the thermostatic circulator Multitemp III (GE Healthcare) at $16^{\circ} \mathrm{C}$, and the power supply was provided by EPS 3500 $\mathrm{XL}$ (GE Healthcare). The isoelectric focusing setup was covered in PlusOne Drystrip Cover Fluid (GE Healthcare). The strips were then equilibrated in $2.5 \mathrm{ml}$ of equilibration buffer I (1.5 M Tris- $\mathrm{HCl}$ buffer, $6 \mathrm{M}$ urea, $4.7 \mathrm{M}$ glycerol, 2\% (w/v) SDS, $16.2 \mathrm{mM}$ DTT) and equilibration buffer II (1.5 M Tris-HCl buffer, 6 M Urea, 4.7 M glycerol, 2\% (w/v) SDS, 0.243 $\mathrm{mM} 2$ - iodoacetamide) for 15 minutes.

SDS-PAGE on the strips was done in $12 \%$ resolving and $4 \%$ stacking gel, embedded with $0.5 \%$ agarose containing trace bromophenol blue. The electrophoresis processes were performed as described by the instructions of the Mini-Protean II Tetra Cell (Bio-Rad) with voltage set to $150 \mathrm{~V}$. 
Electrophoresis was performed in a descending manner with 1X SDS-PAGE running buffer (Bio-Rad) until the dye front reached at the end of the gel. BenchMark ${ }^{\mathrm{TM}}$ Unstained Protein Ladder (Thermo Fisher Scientific Inc.) was concurrently run as standards for estimating molecular weight of protein spots. After SDS-gel electrophoresis, the gel was stained and visualized with Coomassie Brilliant Blue R-250 staining solution (5\% (w/v) Coomassie Brilliant Blue, $85 \%(\mathrm{v} / \mathrm{v})$ ortho-phosphoric acid and ammonium sulphate) for 4 days and destained with $20 \%$ (v/v) methanol until the gel background was clear and clear spots were observed.

\section{Differential expression analysis}

The gel images were processed using the Image Scanner III (GE Healthcare) and Labscan software (GE Healthcare). All of the spot analyses were done using PDQuest software (Bio-Rad) of which the spot detection was done according to Gaussian distribution. The spot intensities were averaged and comparative evaluation on the spot location between control and treated sample were investigated. Ratio of intensity of the same spot in two different gels was determined and the change of intensity was interpreted as change in protein expression. T-test analysis of at 90\% significance ( $p<$ 0.10 ) was also performed using the software. Spots with more than 5 fold of change difference were excised for liquid chromatography tandem mass spectrometry (LC-MS/ MS) analysis. To ensure reliability of the spot identity, spots of similar location on both control and treated gels were identified.

\section{Liquid chromatography tandem mass spectrometry (LC-MS/MS) analysis}

Destaining of the gel plugs were done using $15 \mathrm{mM}$ potassium ferricyanide in $50 \mathrm{mM}$ sodium thiosulphate pentahydrate until transparent. Using $10 \mathrm{mM}$ DTT in $100 \mathrm{mM}$ ammonium bicarbonate and $55 \mathrm{mM}$ iodoacetamide in $100 \mathrm{mM}$ ammonium bicarbonate, the plugs were further reduced and alkylated. Then, the plugs were washed with $50 \%(\mathrm{v} / \mathrm{v})$ acetonitrile in $100 \mathrm{mM}$ ammonium bicarbonate and 100\% (v/v) acetonitrile and followed with dehydration using vacuum centrifugation. The dried plugs were incubated overnight in $25 \mu \mathrm{l}$ of $6 \mathrm{ng} / \mathrm{\mu l}$ trypsin (Sigma-Aldrich) in $50 \mathrm{mM}$ ammonium bicarbonate at $37^{\circ} \mathrm{C}$. The peptides were dried in SpeedVac ${ }^{\mathrm{TM}}$ (Thermo Scientific) and desalted with ZipTipR C18 resin (Merck Milipore). The peptides were dried again and reconstituted in $4 \mu \mathrm{l} 0.1 \%(\mathrm{v} / \mathrm{v})$ formic acid in water. The LC-MS/MS system used was the Agilent 1200 HPLC-Chip/MS Interface, coupled with Agilent 6520 Accurate-Mass $\mathrm{Q}-\mathrm{TOF}$ LC/MS+ ESI. The column used was C18, $160 \mathrm{nl}$ enrichment column and $75 \mu \mathrm{m} \mathrm{x}$ $150 \mathrm{~mm}$ analytical column (Agilent). Flow rate employed was $4 \mu \mathrm{l} / \mathrm{min}$ from Agilent 1200 Series Capillary pump and $0.3 \mu \mathrm{l} / \mathrm{min}$ from Agilent 1200 Series Nano Pump. Sample injection volume was $2 \mu \mathrm{l}$. Solvent A was $90 \%$ acetonitrile in water and solution B was $0.1 \%$ formic acid. Flow rate employed was $4 \mathrm{\mu l} /$ min from Agilent 1200 Series Capillary pump and $0.3 \mu \mathrm{l} / \mathrm{min}$ from Agilent 1200 Series Nano Pump. The solvent gradient employed a stop time at 47 minutes and variation of solvent gradient was optimized for peptide analysis. The spectra were acquired via two modes with the MS scan range of 110-3000 m/z and in the MS/MS the scan range $50-3000 \mathrm{~m} / \mathrm{z}$ was set. For the precursor selection I, the absorbance threshold was 200. Precursor selection II was performed to select fragments of charge states of 2, 3, or more than 3. Data was processed with Agilent Spectrum Mill MS Proteomics Workbench software packages. The scan range for $\mathrm{MH}+$ ion was set from 600 to 4000 Da. Database search was done on SwissProt and National Center for Biotechnology Information (NCBI). \%SPI for peptides were toggled to be more than $60 \%$ and the average distinct summed MS/MS search score over number of peptides was more than 11 . The database selected aimed at current Musca domestica species at Uniprot and SwissprotKB database. The selection of protein entries was based by the notion that the identified entries' MW to be closest to the approximated MW in the 2D gels. 


\section{RESULTS}

The probit analysis has indicated that $\mathrm{H}_{2} \mathrm{O}_{2}$ solution at concentration of $21.5 \%(\mathrm{v} / \mathrm{v})$ would cause $50 \%$ of mortalities of $3^{\text {rd }}$ stage Musca domestica larvae. During the acute treatment of larvae with $\mathrm{H}_{2} \mathrm{O}_{2}\left(\right.$ at $\left.\mathrm{LC}_{50}\right)$, our investigation has also indicated that lipid peroxidation product MDA increased 10 times in the treated larvae. This suggested that the oxidative stress has occurred and changes in the protein expression were due to the effect of the acute peroxide treatment. Proteomic analysis revealed that in the event of acute hydrogen peroxide treatment, 3 proteins were significantly down-regulated more than 5 times $(\mathrm{p}<0.10)$ (actin, ATP: guanido phosphotransferase, ubiquitin) and up-regulated (tropomyosin, arginine kinase, PBP/GOBP family protein). In thiolated proteome, a short chain/alcohol dehydrogenase like protein and lactate dehydrogenase were down-regulated more than 5 fold. The study also demonstrated that arginine kinase and fructose-bisphosphate aldolase were upregulated more than 5 fold. The changes of the selected proteins were visualized in Figure 1. Table 1 summarizes the quantitative analysis of the change in expression and the identification of the spots. As the \% SPI for peptides were more than $60 \%$ and the average distinct summed MS/MS search score over number of peptides was more than 11 (distinct peptide score that implies a significant protein identification), our results are sufficiently valid. In our study, the protein expression was solely investigated to imply the correlation between acute treatment and expression of cytosolic and thiolated proteins.

\section{DISCUSSIONS}

Actin levels were reduced while tropomyosin levels were elevated in hydrogen peroxide challenged housefly larvae. Actin (monomer; G-actin: globular actin) polymerizes into filaments better known as F-actin (filamentous actin) under physiological conditions to form cytoskeleton in cells (Huber et al., 2013). Tropomyosin on the other hand stabilizes actin filament and mediates actin binding proteins in muscular tissues (Cooper, 2002). Muscle enhancer MEF2 which regulates Drosophila TmI gene in muscles in larvae (Lin \& Stroti, 1997) is switched on during oxidative stress. Clam Chamaelea gallina which were exposed to Aroclor 1254 and copper(II), had the actin gene downregulated while the putative isoforms of tropomyosin were upregulated (Rodríguez Ortega et al., 2003).

Oxidative challenge on housefly larvae might also affect the cellular ubiquitin proteasomal activity. Based on the results, ubiquitin abundance reduced in the event of the oxidative stress (7.90 times downregulation, Spot C, Figure 1), suggesting a disruption or a shift of homeostasis of ubiquitin. A 76-residue polypeptide, ubiquitin is highly conserved and present in all eukaryotes (Goldstein et al., 1975). The decrease of monomeric ubiquitin could be accounted to the attack on the Cys residues in ubiquitin conjugating enzymes in ubiquitinproteasome pathway, regulated via E1 (ubiquitin-activating enzymes), E2 (ubiquitin conjugating enzymes) and E3 (ubiquitin ligase enzymes). E1 activates Gly residue of ubiquitin to Cys residue to generate high energy thiolester intermediate (E1 S ubiquitin), while E2 relays the activated ubiquitin from $\mathrm{E} 1$ via an internal Cys residue as well (Ye \& Rape, 2009). Decrease of ubiquitin pool in oxidatively challenged housefly larvae might be also due to the viability of deubiquitinating enzymes (DUBs), which catalyze the process of breaking down ubiquitinated substrates/ free polyubiquitin chain in the cell (Amerik \& Hochstrasser, 2004) and the synthesis of ubiquitin (Redman \& Rechsteiner, 1989). DUB's catalytic site consists of highly conserved regions of histidine and cysteine boxes (Reyes-Turcu et al., 2006). It is conceivable that oxidative damage occurred in Cys residues on the ubiquitin conjugating and deubiquitination enzymes, causing the decrease in ubiquitin.

Fast alternative energy metabolism and ATP buffering possibly occurred during oxidative stress. Arginine kinase (8.97 fold increase, spot E, Figure 1) catalyzes 


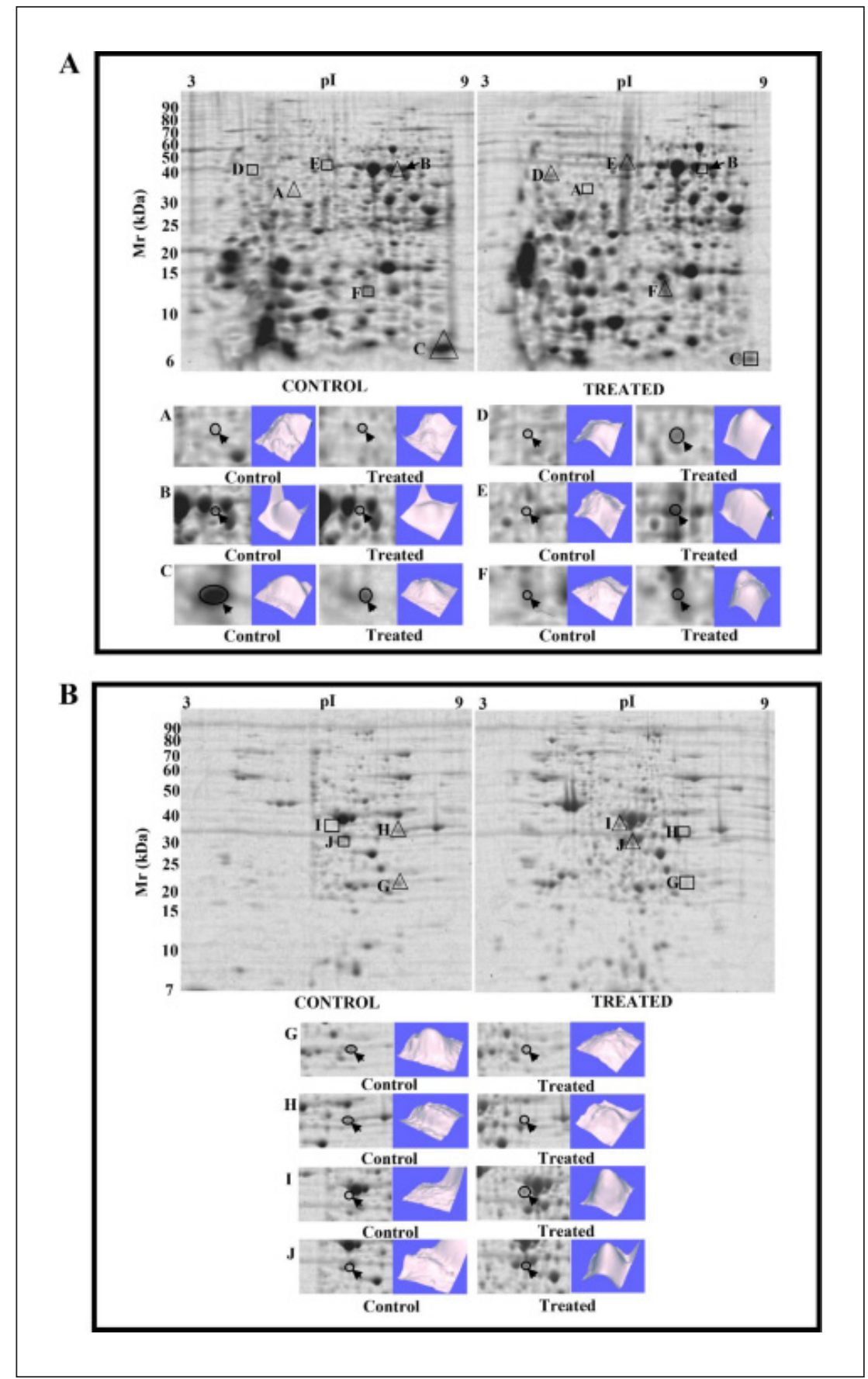

Figure 1. Spots position of proteome expression profile on more than $5 \mathrm{x}$ fold change in of Musca domestica $3^{\text {rd }}$ stage larvae.

Box A shows comparative investigation of cytosolic proteome profile of which spots were designated from A-F in Box A. The 3-D presentation of the compared spots was made to visually compare the spot intensity. Box B indicates thiolated protein spots designated from G-J that had expression change more than 5 fold. The spots were either identified in $\Delta$ and $\square$ on both gels to indicate changes ( $>5$ fold change) in protein expression of the same protein in control and treated gel. The respective $3 \mathrm{D}$ images of the comparative protein spots were shown below the gel images. Arrows indicate the location of the spots on two different gels. Gels were stained with Coomassie Blue. 


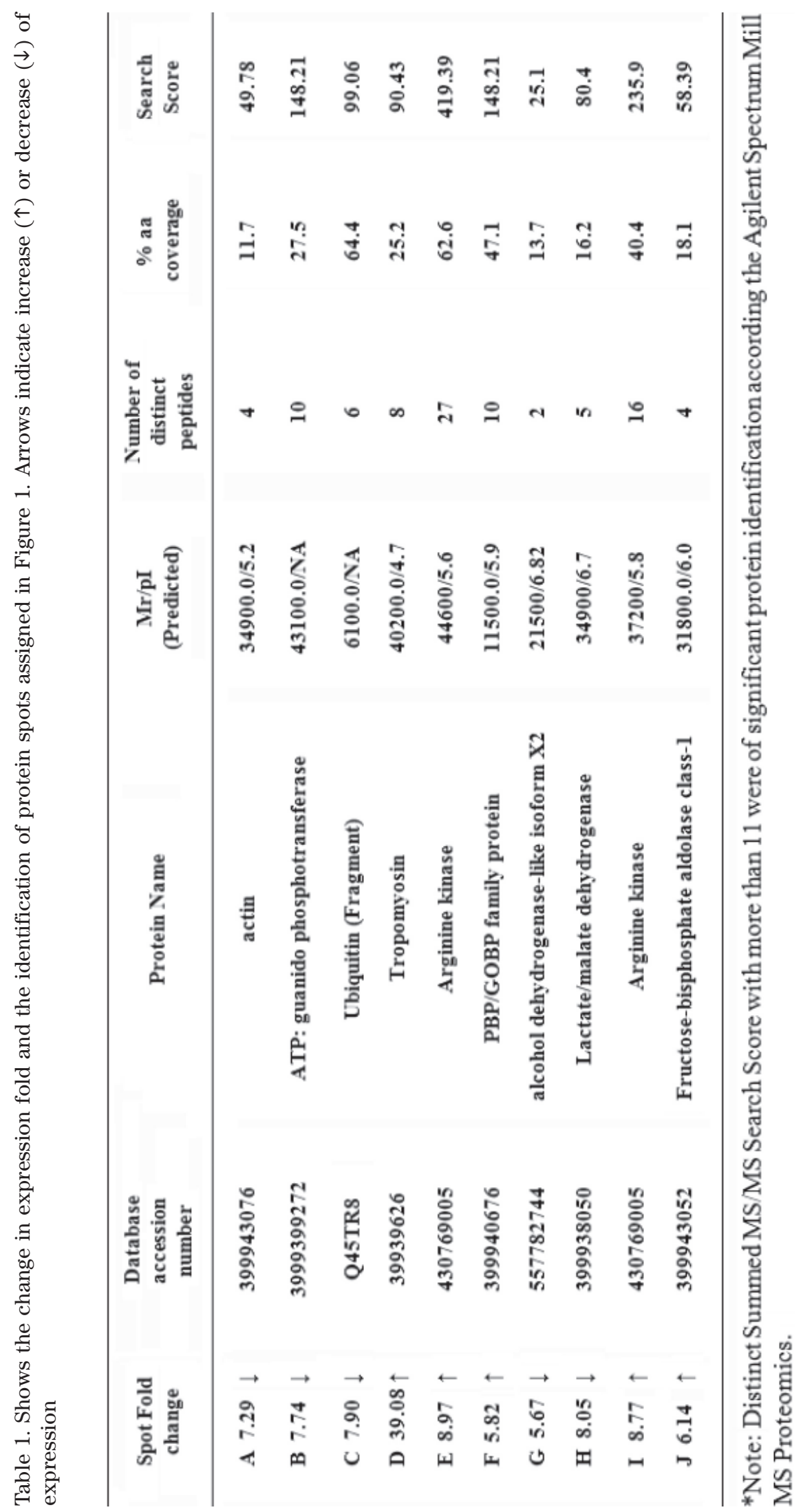


the reversible reaction of transferring phosphorus group between MgATP and arginine acting as energy-storing phosphagen. Phosphoarginine is one of the phosphagen in living systems, smaller than ATP and able to diffuse to provide fast energy supply (Ellington, 2001) enabling cells to restore ATP levels during bursts of cellular events such as in nerves and muscles (Hird, 1986). Miranda et al. (2006) demonstrated the increment of arginine kinase rates increased during hypoxia. Arginine kinase was detected in high fold changes in cytosolic proteome (8.97 fold) and thiolated proteome (8.77 fold). This suggested that Musca domestica larvae highly expresses arginine kinase, at the same time highly protects this protein from oxidative modification by hydrogen peroxide. Thus, we suggested that arginine kinase could be vital in Musca domestica larvae's energy metabolism response. utilizing phosphoarginine to provide alternative cellular energy source and ATP buffering during oxidative stress.

Other protein responses in high level expression during oxidative challenge including a protein from ATP:guanidino phosphotranferase family, which expressed 7.74 fold higher than in control replicates (Spot B, Figure 1). ATP:guanidino phosphotransferases catalyzes the transfer of phosphate between phosphagens and ATP (Stein et al., 1990). Arginine kinase exists in mitochondrial and cytoplasm in isoforms (Munneke \& Collier, 1988). Thus, it is important to identify and characterize specific isoform that participated in responses to oxidative stress. $\mathrm{PBP} / \mathrm{GOBP}$ protein family (pheromone binding protein/ general odorant binding protein) from Spot $F$ (Figure 1) has shown an increase of 5.82 fold of expression in treated samples. The protein is localized in the aqueous fluid around olfactory sensory dendrites to bind and transport hydrophobic odorants (Vogt \& Riddiford, 1981). PBP, binds specifically towards pheromone (Du \& Prestwich, 1995) while GOBP associate with general-odorant sensitive neurons (Vogt et al., 1991). Further investigation is needed to understand its correlation to oxidative stress.
Arginine kinase are present in the thiol proteome profile (Spot I, Figure 1), possibly due to its conserved residue Cys271 at the active site of arginine kinase (Zhou et al., 1998). The overexpression of arginine kinase as an effect of oxidative stress has been discussed. As the non-thiolated protein was removed, we observed enhancement of a glycolytic enzyme during acute peroxide treatment. There was a 6.14 fold increase (Spot J, Figure 1) in expression of fructose bisphosphate aldolase in treated samples. The enzyme catalyzes the forward reaction of aldol splitting of fructose 1,6-bisphosphate to dihydroxyacetone phosphate to glyceraldehyde 3-phosphate and the reverse reaction (Gardberg et al., 2011). Sequence analysis by Brenner-Holzach (1979) however showed no exposed thiol groups of Drosophila melanogaster's fructose bisphosphate aldolase. Interestingly, Bourrett et al. (2001) reported that fructose bisphosphate aldolase of Borrelia burgdorferi was able to sustain nitrosative damage on its cysteine thiols. Changes involved in glycolytic enzymes expression is an interesting entry point to further understand oxidative stress responses in energy metabolism.

Spot G (Figure 1) is a short-chain alcohol dehydrogenase, which is a ubiquitous $\mathrm{NAD}(\mathrm{P})(\mathrm{H})-$ dependent enzyme. Our study indicated a decrease of the protein expression under acute treatment at 5.67 fold. It was easily purified due to the fact that it has Cys-218 (which is in proximity to NAD+ binding site and does not have any catalytic properties) (Chen et al., 1990) and two other solvent facing cysteine residues (Mayoral et $a l ., 2013)$. Proteins that belong to this family have low pairwise sequence identity (15\%30\%) (Filling et al., 2002). Thus, it is still far from conclusive that which short chain dehydrogenase of $3^{\text {rd }}$ stage larvae of $M u s c a$ domestica was responsive towards oxidative stress. Present in 8.05 fold decrease in expression was a protein that belongs to lactate/malate dehydrogenase family (Spot H, Figure 1). Both lactate/malate dehydrogenases catalyze the conversion of 2-hydroxy acids to the corresponding 2-keto acids 
(Birktoft et al., 1982). Lactate dehydrogenases are important enzymes in anaerobic metabolism, by interconverting lactate to pyruvate utilizing $\mathrm{NAD}(\mathrm{P}) / \mathrm{NAD}(\mathrm{P})(\mathrm{H})$ (Holbrook et al., 1975). A highly-conserved cysteine residue, Cys-165 located at the proximity of co-substrate binding site (Taylor et al., 1973) possibly allowed its selection into our purification protocol. Oxidative stress has been shown to overexpress lactate dehydrogenase favouring anaerobic respiration instead of bringing it down (Oliveira \& Oliveira, 2002). Decrease of lactate dehydrogenase in our experiment might be just a physiological event of the extracellular leakage rather than metabolic, caused by the damage of plasma membrane during cell death (Bagchi et al., 1995).

\section{CONCLUSION}

We have successfully discovered potential protein biomarkers during acute hydrogen peroxide treatment performed on Musca domestica $3^{\text {rd }}$ stage larvae via two dimensional gel electrophoresis and LC-MS/MS identification. Protein with high-fold changes in expression identified in the proteome involved in biological processes such as cytoskeletal network (actin and tropomyosin), ubiquitin proteasomal activity (ubiquitin), and alternative energy metabolism (arginine kinase). A glycolytic enzyme (fructose bisphosphate aldolase) and arginine kinase changed in expression in hydrogen peroxide treated samples from the thiol proteome profile. We identified other proteins from cytosolic proteome profile (PBP/GOBP and ATP:guanidino phosphotranferase family) and thiol proteome profile (lactate/malate dehydrogenase and PBP/GOBP family protein), however understanding their role in oxidative stress response requires further investigation. We hope through this discovery we can provide more insights on oxidative stress defence in houseflies in future.

\section{Conflict of Interest}

There is no conflict of interests that could be perceived as prejudicing the impartiality of the research reported.

Acknowledgement. The work has been funded by University of Malaya Postgraduate Research Fund (PPP: PV091/2011A) and Ministry of Higher Education under the Fundamental Research Grant (FRGS: FP0522014A).

\section{REFERENCES}

Amerik, A.Y. \& Hochstrasser, M. (2004). Mechanism and function of deubiquitinating enzymes. Biochimica et Biophysica Acta 1695: 189-207.

Bagchi, D., Bagchi, M., Hassoun, E.A. \& Stohs, S.J. (1995). In vitro and in vivo generation of reactive oxygen species, DNA damage and lactate dehydrogenase leakage by selected pesticides. Toxicology 104(1): 129-140.

Barford, D. (2004). The role of cysteine residues as redox-sensitive regulatory switches. Current Opinion in Structural Biology 14: 679-686.

Barin, A., Arabkhazaeli, F., Rahbari, S. \& Madani, S.A. (2010). The housefly, Musca domestica, as a possible mechanical vector of Newcastle disease virus in the laboratory and field. Medical and Veterinary Entomology 24: 88-90.

Birktoft, J.J., Fernley, R.T., Bradshaw, R.A. \& Banaszak, L.J. (1982). Amino acid sequence homology among the 2hydroxy acid dehydrogenases: mitochondria land cytoplasmic malate dehydrogenases form a homologous system with lactate dehydrogenase. Proceedings of the National Academy of Sciences of the United States of America 79(20): 6166-6170. 
Boulesteix, G., Le Dantec, P., Chevalier, B., Dieng, M., Niang, B. \& Diatta, B. (2005). Role of Musca domestica in the transmission of multiresistant bacteria in the centres of intensive care setting in a sub-Saharan Africa. Annales Françaises d'Anesthésie et de Réanimation 24: 361365.

Bourrett, T.J., Boylan, J.A., Lawrence, K.A. \& Gherardini, F.C. (2011). Nitrosative damage to free and zinc-bound cysteine thiols underlies nitric oxide toxicity in wild-type Borrelia burgdorferimmi. Molecular Microbiology 81(1): 259-273.

Brandes, N., Rinck, A., Leichert, L.I. \& Jakob, U. (2007). Nitrosative stress treatment of $E$. coli targets distinct set of thiol containing proteins. Molecular Microbiology 66: 901-914.

Brenner-Holzach, O. (1979). Fructose 1,6diphosphate aldolase of Drosophila melanogaster: Comparative sequence analyses of the cysteine-containing peptides. Archives of Biochemistry and Biophysics 194: 328-335.

Chen, Z., Lu, L., Shirley, M., Lee, W.R. \& Chang, S.H. (1990). Site-directed mutagenesis of glycine 14 and two "critical" cysteinyl residues in Drosophila alcohol dehydrogenase. Biochemistry 29(5): 1112-1118.

Cooper, J.A. (2002). Actin dynamics: tropomyosin provides stability. Current Biology 12(15): R523-R525.

Dabas, A., Nagpure, N.S., Kumar, R., Kushwaha, B., Kumar, P. \& Lakra, W.S. (2012). Assessment of tissue specific effect of cadmium on antioxidant defense system and lipid peroxidation in freshwater murrel, Channa punctatus. Fish Physiology and Biochemistry 38(2): 469-82.

Dahlem, G. (2003). House Fly (Musca domestica). In: Encyclopedia on Insects, Vol. 1, Resh, V and Carde, R. (editors) $1^{\text {st }}$ edition. San Diego: Academic Press, pp. 532-534.

Du, G. \& Prestwich, G.D. (1995). Protein structure encodes the ligand binding specificity in pheromone binding proteins. Biochemistry 34(27): 87268732.
Ellington, W.R. (2001). Evolution and physiological roles of phosphagen systems. Annual Review of Physiology 63(1): 289-325.

Filling, C., Berndt, K.D., Benach, J., Knapp, S., Prozorovski, T., Nordling, E., Ladenstein, R., Jörnvall, H. \& Oppermann, U. (2002). Critical residues for structure and catalysis in short-chain dehydrogenases/ reductases. Journal of Biological Chemistry 277(28): 25677-25684.

Finney, D.J. (1947). Probit analysis: a statistical treatment of the sigmoid response curve. Oxford: Cambridge University Press, pp. 256.

Gardberg, A., Abendroth, J., Bhandari, J., Sankaran, B. \& Staker, B. (2011). Structure of fructose bisphosphate aldolase from Bartonella henselae bound to fructose 1,6-bisphosphate. Acta Crystallography Section F: Structural Biology Communications 67(Pt 9): 1051-1054.

Goldstein, G., Scheid, M., Hammerling, U., Schlesinger, D.H., Niall, H.D. \& Boyse, E.A. (1975). Isolation of a polypeptide that has lymphocyte differentiating properties and is probably represented universally in living cells. Proceedings of the National Academy of Sciences USA 72(1): 11-15.

Grubel, P., Hoffman, J.S., Chong, F.K., Burstein, N.A., Mepani, C. \& Cave, D. (1997). Vector potential of houseflies (Musca domestica) for Helicobacter pylori. Journal of Clinical Microbiology 35: 1300-1303.

Hird, F.J. (1986). The importance of arginine in evolution. Comparative Biochemistry and Physiology 85(2): 285-288.

Holbrook, J.J., Liljas, A., Steindel, S.J. \& Rossmann, M.G. (1975). Lactate dehydrogenase. In: The Enzymes, Boyer, P.D. (editor). New York: Academic Press. pp. 191-292.

Hu, W., Tedesco, S., McDonagh, B., Barcena, J.A., Keane, K. \& Sheehan, D. (2010). Selection of thiol and disulfidecontaining proteins of Escherichia coli on activated thiol-Sepharose. Analytical Biochemistry 398: 245-253. 
Huber, F., Schnauss, J., Rönicke, S., Rauch, P., Müller, K., Fütterer, C. \& Käs, J. (2013). Emergent complexity of the cytoskeleton: from single filaments to tissue. Advances in Physics 62(1): 1-112.

Kale, M., Rathore, N., John, S. \& Bhatnagar, D. (1999). Lipid peroxidative damage on pyrethroid exposure and alterations in antioxidant status in rat erythrocytes: a possible involvement of reactive oxygen species. Toxicology Letters 105: 197-205.

Klose, J. (1975). Protein mapping by combined isoelectric focusing and electrophoresis of mouse tissues. A novel approach to testing for induced point mutations in mammals. Humangenetik 26: 231-243.

Koner, B.C., Banerjee, B.D. \& Ray, A. (1998). Organochlorine pesticideinduced oxidative stress and immune suppression in rats. Indian Journal of Experimental Biology 36(4): 395-398.

Kočišová, A., Petrovský, M., Toporčák, J. \& Novák, P. (2004). The potential of some insect growth regulators in housefly (Musca domestica) control. Biologia 59: 661-668.

Kristensen, M. \& Jespersen, J.B. (2003). Larvicide resistance in Musca domestica (Diptera: Muscidae) populations in Denmark and establishment of resistant laboratory strains. Journal of Economic Entomology 96(4): 1300-1306.

Lin, S.C. \& Storti, R.V. (1997). Developmental regulation of the Drosophila tropomyosin I (TmI) gene is controlled by a muscle activator enhancer region that contains multiple cis-elements and binding sites for multiple proteins. Development Genetics 20(4): 297-306.

Lukaszewicz-Hussain, A. (2010). Role of oxidative stress in organophosphate insecticide toxicity - Short review. Pesticides Biochemistry and Physiology 98: $145-50$.

Marçon, P.C.R.G., Thomas, G.D., Siegfried, B.D., Campbell, J.B. \& Skoda, S.R. (2003). Resistance status of house flies (Diptera: Muscidae) from southeastern Nebraska beef cattle feedlots to selected insecticides. Journal of Economic Entomology 96(3): 1016-1020.
Mayoral, J.G., Leonard, K.T., Nouzova, M. Noriega, F.G., Defelipe, L.A. \& Turjanski, A.G. (2013). Functional analysis of a mosquito short-chain dehydrogenase cluster. Archives of Insect Biochemistry and Physiology 82(2): 96-115.

Miranda, M.R., Canepa, G.E., Bouvier, L.A. \& Pereira, C.A. (2006). Trypanosoma cruzi: oxidative stress induces arginine kinase expression. Experimental Parasitology 114(4): 341-344.

Munneke, L.R. \& Collier, G.E. (1988). Cytoplasmic and mitochondrial arginine kinases in Drosophila: Evidence for a single gene. Biochemical Genetics 26(12): 131-141.

O'Farrell, P.H. (1975). High-resolution twodimensional electrophoresis of proteins. Journal of Biological Chemistry 250: 4007-4021.

Oliveira, P.L. \& Oliveira, M.F. (2002). Vampires, Pasteur and reactive oxygen species: Is the switch from aerobic to anaerobic metabolism a preventive antioxidant defence in blood-feeding parasites? FEBS Letters 525: 3-6.

Redman, K.L. \& Rechsteiner, M. (1989). Identification of the long ubiquitin extension as ribosomal protein S27a. Nature 338: 438-440.

Reyes-Turcu, F.E., Horton, J.R., Mullally, J.E., Heroux, A., Cheng, X. \& Wilkinson, K.D. (2006). The ubiquitin binding domain ZNF UBP recognizes the $\mathrm{C}$ terminal diglycine motif of unanchored ubiquitin. Cell 124(6): 1197-1208.

Rodríguez-Ortega, M.J., Grøsvik, B.E., Rodríguez-Ariza, A., Goksøyr, A. \& LópezBarea, J. (2003). Changes in protein expression profiles in bivalve molluscs (Chamaelea gallina) exposed to four model environmental pollutants. Proteomics 3(8): 1535-1543.

Scott, J.G., Alefantis, T.G., Kaufman, P.E. \& Rutz, D.A. (2000). Insecticide resistance in house flies from caged-layer poultry facilities. Pest Management Science 56: $147-153$. 
Scott, J.G., Liu, N., Kristensen, M. \& Clark, A.G. (2009). A case for sequencing the genome of Musca domestica (Diptera: Muscidae). Journal of Medical Entomology 46(2): 175-182.

Scott, J.G., Warren, W.C., Beukeborn, L.W., Bopp, D., Clark, A.G., Giers, S.D., Hedger, M., Jones, A.K., Kasai, S., Leichter, C.A., Li, M., Meisel, R.P., Minx, P., Murphy, T.D., Nelson, D.R., Reid, W.R., Rinkevich, F.D., Robertson, H.M., Sackton, T.B., Sattelle, D.B., Thibaud Nissen, F., Tomlinson, C., van de Zande, L., Walden, K.K.O., Wilson, R.K. \& Liu, N. (2014). Genome of the house fly, Musca domestica L., a global vector of diseases with adaptations to a septic environment. Genome Biology 15(466).

Simmons, T.W., Jamail, I.S. \& Lockshin, R.A. (1987). The effect of selenium deficiency on peroxidative injury in the house fly, Musca domestica: A role for glutathione peroxidase. FEBS Letters 218(2): 251254.

Stein, L.D., Harn, D.A. \& David, J.R. (1990). A cloned ATP: guanidino kinase in the trematode Schistosoma mansoni has a novel duplicated structure. Journal of Biological Chemistry 265(12): 65826588.

Szalanski, A.L., Owens, C.B., Mckay, T. \& Steelman, C.D. (2004). Detection of Campylobacter and Escherichia coli O157:H7 from filth flies by polymerase chain reaction. Medical and Veterinary Entomology 18: 241-246.

Taylor, S.S., Oxley, S.S., Allison, W.S. \& Kaplan, N.O. (1973). Amino acid sequence of dogfish M4 lactate dehydrogenase. Proceedings of the National Academy of Sciences of the United States of America 70(6): 1790-1793.
Tedesco, S., Doyleb, H., Blascoc, J., Redmond, G. \& Sheehan, D. (2010). Oxidative stress and toxicity of gold nanoparticles in Mytilus edulis. Aquatic Toxicology 100: 178-186.

van Montfort, R.L., Congreve, M., Tisi, D., Carr, R. \& Jhoti, H. (2003). Oxidation state of the active site cysteine in protein tyrosine phosphatase 1B. Nature 423: 773-777.

Velu, C.S., Niture, S.K., Doneanu, C.E., Pattabiraman, N. \& Srivenugopal, K.S. (2007). Human p53 is inhibited by glutathionylation of cysteines present in the proximal DNA-binding domain during oxidative stress. Biochemistry 46(26): 7765-7780.

Vogt, R.G. \& Riddiford, L.M. (1981). Pheromone binding and inactivation by moth antennae. Nature 293: 161-163.

Vogt, R.G., Prestwich, G.D. \& Lerner, M.R. (1991). Odorant-binding-protein subfamilies associate with distinct classes of olfactory receptor neurons in insects. Journal of Neurobiology 22(1): 74-84.

Ye, Y. \& Rape, M. (2009). Building ubiquitin chains: E2 enzymes at work. Nature Reviews Molecular Cell Biology 10(7): 55-64.

Yin, Z., Ivanov, V.N., Habelhah, H., Tew, K. \& Ronai, Z. (2000). Glutathione Stransferase elicits protection against $\mathrm{H}_{2} \mathrm{O}_{2}$-induced cell death via coordinated regulation of stress kinases. Cancer Research 60: 4053-4057.

Zhou, G., Somasundaram, T., Blanc, E., Parthasarathy, G., Ellington, W.R. \& Chapman, M.S. (1998). Transition state structure of arginine kinase: implications for catalysis of bimolecular reactions. Proceedings of the National Academy of Sciences of the United States of America 95(15): 8449-8454. 